\title{
Aspectos da importância do complexo soja no Brasil e no Rio Grande do Sul: 1997 - 2017
}

\author{
Nilson Luiz Costa \\ Universidade Federal de Santa Maria - Palmeira das Missões - RS - Brasil \\ ORCID: http://orcid.org/0000-0003-2000-1521 \\ Antônio Cordeiro de Santana \\ Universidade Federal Rural da Amazônia - Belém - PA - Brasil \\ ORCID: https://orcid.org/0000-0002-4324-9178 \\ Daniel Arruda Coronel \\ Universidade Federal de Santa Maria - Santa Maria - RS - Brasil \\ ORCID: https://orcid.org/0000-0003-0264-6502 \\ Argemiro Luís Brum \\ Universidade Regional do Noroeste do Estado do Rio Grande do Sul - ljuí - RS - \\ Brasil \\ ORCID: https://orcid.org/0000-0002-8763-9514 \\ Carlos André Corrêa de Mattos \\ Universidade Federal do Pará - Belém - PA - Brasil \\ ORCID: https://orcid.org/0000-0002-3027-7479
}

\section{Resumo}

O objetivo da presente pesquisa foi o de analisar a importância do agronegócio para a economia brasileira e gaúcha, especificamente nas questões relacionadas às exportações e na capacidade de a lavoura de soja estimular negócios nos segmentos de sementes, fertilizantes e defensivos nas distintas mesorregiões do estado do Rio Grande do Sul. A pesquisa pode ser classificada como exploratório-descritiva quanto aos fins e como estudo de caso quanto aos meios. Entre os principais resultados, destaca-se que o agronegócio se constitui em um dos principais segmentos da economia brasileira e a sua importância é comprovada pela capacidade de agregar renda e elevar o saldo comercial até mesmo em momentos de crise econômica. Também foi possível observar que a cadeia produtiva da soja, além de gerar renda e saldo comercial no Brasil e no Rio Grande do Sul, agrega um conjunto de atividades com potencial para estimular as relações econômicas em nível local, se constituindo enquanto atividade catalisadora de negócios e capaz de estimular segmentos da indústria associados a produção de insumos para as lavouras.

Palavras-chave: Comércio Exterior. Complexo Soja. Comércio Varejista. Insumos. 


\section{Aspect of the importance of soybean complex in Brazil and Rio Grande do Sul: 1997 - 2017 Abstract}

The objective of the present research was to analyze the importance of agribusiness for the Brazilian and Rio Grande do Sul economy, specifically on issues related to exports and the ability of soybean farming to stimulate business in the seeds, fertilizers and pesticides segments in the different mesoregions of Rio Grande do Sul State/Brazil. The research can be classified as exploratory-descriptive as to the purposes and as a case study regarding the means. Among the main results, it is worth noting that agribusiness is one of the main segments of the Brazilian economy and its importance is proven by the capacity to add income and raise the trade balance even in times of economic crisis. It was also possible to observe that the soybean production chain, in addition to generating income and trade balance in Brazil and Rio Grande do Sul State, aggregates a set of activities with potential to stimulate economic relations at the local level, constituting as a business catalyst activity and capable of stimulating industry segments associated with the production of crop inputs.

Keywords: Foreign Trade. Soybeans Complex. Retail business. Inputs.

\section{Aspectos de la importancia del complejo soja en Brasil y en el Río Grande del Sur: 1997 - 2017}

\section{Resumen}

El objetivo de la presente investigación fue el de analizar la importancia del agronegocio para la economía brasileña y gaúcha, específicamente en las cuestiones relacionadas a las exportaciones y en la capacidad de la labranza de soja estimular los negocios en los segmentos de semillas, fertilizantes y defensivos en las distintas mesorregiones del mismo, el estado de Rio Grande do Sul. La investigación puede ser clasificada como exploratoriodescriptiva en cuanto a los fines y como estudio de caso en cuanto a los medios. Entre los principales resultados, se destaca que el agronegocio se constituye en uno de los principales segmentos de la economía brasileña y su importancia es comprobada por la capacidad de agregar renta y elevar el saldo comercial incluso en momentos de crisis económica. También se pudo observar que la cadena productiva de la soja, además de generar ingresos y saldo comercial en Brasil y en Rio Grande do Sul, agrega un conjunto de actividades con potencial para estimular las relaciones económicas a nivel local, constituyéndose como actividad catalizadora de negocios y capaz de estimular segmentos de la industria asociados a la producción de insumos para las labranzas.

Palabras clave: Comercio Exterior. Complejo Soja. Comercio al por menor. Insumos

\section{Introdução}

O Rio Grande do Sul possui atividade econômica baseada em diversos setores que respondem por parte da demanda interna por produtos básicos e industrializados e ao mesmo tempo posicionam o estado entre os maiores exportadores brasileiros.

Nas áreas tradicionalmente agrícolas, como as da mesorregião Noroeste RioGrandense, o cultivo de grãos e cereais com fins comerciais se intensificou a partir das décadas de 1960/70 e resultou na criação de uma extensa cadeia produtiva, com mercados estruturados nos segmentos de insumos agrícolas, recebimento e processamento de grãos (BRUM, 1992). 
Em decorrência das soluções apresentadas pelos segmentos de sementes, fertilizantes e defensivos agrícolas, os agricultores passaram a encontrar, em suas relações comerciais com empresas e cooperativas vinculados ao mercado varejista de insumos agrícolas. Este é um importante canal de acesso a novas tecnologias, que passaram a contribuir com os sucessivos aumentos na produtividade. Estas, por sua vez, associadas às expetativas de lucro, resultaram em um processo de avanço da lavoura de soja para regiões que há poucos anos eram exclusivamente exploradas pela pecuária (THEISEN; VERNETTI JUNIOR; SILVA, 2009).

Esta relação dos produtores de soja com os fornecedores de insumos e tecnologias e com empresas que distribuem o produto para agroindústrias e para o mercado internacional, formam os encadeamentos para trás e para frente propostos por Hirschman (1988) e aplicados ao agronegócio brasileiro por Santana e Campos (1994) e às cadeias agropecuárias do estado do Pará por Gomes et al. (2016). Esta conexão norteia esta pesquisa para avaliar em que medida a lavoura de soja contribuiu para o estabelecimento de atividades retrospectivas, para 0 faturamento bruto das empresas e cooperativas que atuam no segmento de venda de sementes, fertilizantes e defensivos no estado do Rio Grande do Sul e para as exportações brasileiras?

O objetivo da presente pesquisa foi o de analisar a importância da cadeia produtiva da soja nas exportações brasileiras do agronegócio, o volume de negócios com sementes, fertilizantes e defensivos que configuram os encadeamentos da lavoura de soja nas distintas mesorregiões do estado do Rio Grande do Sul e a tendência do segmento nos próximos anos. Portanto, a análise é feita por meio do comportamento histórico das variáveis que representam os fornecedores de insumos e dos que comercializam os produtos.

A importância econômica da cadeia produtiva da soja foi analisada sob a ótica quantitativa de análise de dados secundários, principalmente relacionados à participação do segmento nas exportações. As tendências de crescimento e intensificação das atividades do segmento foram amparadas em modelos econométricos de taxa de crescimento.

O volume de capital investindo pelos sojicultores gaúchos em sementes, defensivos e fertilizantes, bem como a margem de comercialização do mercado varejista, foi mensurado a partir dos custos de produção divulgados por Brasil (2018; 2018d).

Identificou-se que as exportações do agronegócio são de extrema importância para o saldo comercial brasileiro e gaúcho e que a lavoura de soja, além de contribuir para o acúmulo de reservas internacionais, tem a capacidade de estimular negócios e apropriar renda em segmentos como o que fornece sementes, fertilizante e defensivos, em todas as regiões do estado do Rio Grande do Sul.

O presente artigo está dividido em quatro seções, sendo esta a primeira. $\mathrm{Na}$ segunda parte são apresentados os "Materiais e Métodos", em seguida os "Resultados e Discussões" (terceira seção) e as "Considerações Finais" (seção 4). 


\section{Material e Métodos}

De acordo com a taxonomia proposta por Vergara (2014), esta pesquisa pode ser classificada como exploratório-descritiva quanto aos fins e como estudo de caso quanto aos meios. A importância econômica do agronegócio e da cadeia produtiva da soja foi analisada a partir da interpretação de dados secundários disponíveis no Centro de Estudos Avançados em Economia Aplicada (CEPEA, 2017) e Brasil (2018a; 2018b).

2.1 Método utilizado para mensurar o valor econômico do comércio de insumos de soja

Para fins de análise e tabulação de dados estatísticos, a pesquisa considerou o conceito de mesorregião adotado pelo Instituto Brasileiro de Geografia e Estatística (BRASIL, 1990).

A estimação do volume de negócios resultante das relações de compra e venda nos segmentos de sementes, defensivos e fertilizantes, por mesorregião geográfica, procedeu-se a partir da seguinte equação:

$V k_{t i}=C I_{i} * A p_{t}$

Em que: $V k_{t i}$ é o valor econômico do insumo i investido no tempo t, sendo $\mathrm{i}=\left(\right.$ sementes ou fertilizantes ou defensivos); $C I_{i}$ é o custo/ha do insumo i, dado por Brasil (2016); $A p_{t}$ é a área plantada de soja, nas mesorregiões do RS, no ano t.

A margem de comercialização do comércio varejista foi mensurada através da seguinte equação, conforme Mendes e Padilha Junior (2007):

$M v_{t}=P v_{t}-P a_{t}$

Em que: $M v_{t}$ é a margem bruta de comercialização do varejo; $P v_{t}$ é o preço de Varejo, e; $P a_{t}$ é o preço de Atacado.

Neste contexto, a análise realizada considerou a existência de um sistema de comercialização simplificado, composto por três grupos, sendo o primeiro formado pelo comércio atacadista de insumos agrícolas (formado pelas organizações responsáveis por disponibilizar os insumos para o comércio varejista, geralmente multinacionais); o segundo, pelo comércio varejista de insumos agrícolas, caracterizado pelo grande número de empresas e cooperativas de abrangências local/regional que se constituem, de fato, como o principal canal de comercialização dos insumos agrícolas.

Para este estudo, todos os dados expressos em Reais (R\$) foram corrigidos pelo Índice Geral de Preços-Disponibilidade Interna (IGP-DI) e estão expressos em valores reais de 2017. As informações expressas em dólares (US\$) foram corrigidas para a data base $2017=100$, pelo Índice de Preços ao Consumidor dos Estados Unidos, disponibilizado pelo United States Department of Labor (2018).

Com o objetivo de identificar as margens médias de comercialização médias, nas vendas do comércio varejista de sementes, fertilizantes e defensivos para a lavoura de soja, foram realizadas entrevistas com dois especialistas (empresários com larga experiência neste ramo de atividade econômica). 


\subsection{Modelo econométrico de taxa de crescimento}

O modelo econométrico de taxa de crescimento, proposto por Santana (2003), Greene (2008) e Rhoden et al. (2020), foi utilizado para identificar os componentes de tendências nas séries analisadas. A tendência de crescimento pode ser obtida através da estimação das equações 3 e 4.

$V k_{t i}=\alpha+\beta_{1}$ Tend $+\varepsilon$

Em que: $V k_{t i}$ é o valor econômico do insumo i investido no tempo t, sendo $\mathrm{i}=($ sementes, fertilizantes ou defensivos); $\alpha$ é a constante ou intercepto da regressão; $\beta_{1}$ é o coeficiente de tendência da regressão; Tend é a variável de tendência; $\varepsilon$ é o termo de erro estocástico.

$\mathrm{Na}$ equação 3, o coeficiente de tendência $\beta_{1}$ representa o incremento médio anual, em unidades, no valor de $V k_{t i}$, para cada aumento de uma unidade na variável de tempo. Substituindo-se, na equação 3, a variável $V k_{t i}$ por $\ln V k_{t i}$, tem-se a equação 4:

$\operatorname{lnV} k_{t i}=\alpha+\beta_{1}$ Tend $+\varepsilon$

Em que: $\ln V k_{t i}$ é o logaritmo natural do valor econômico do insumo i investido no tempo $t$, sendo $\mathrm{i}=$ (sementes, fertilizantes ou defensivos);

$\mathrm{Na}$ equação 4 , o coeficiente de tendência $\beta_{1}$ representa o crescimento médio, em termos percentuais, no valor de $V k_{t i}$, para cada aumento de uma unidade na variável de tempo.

Realizou-se o cálculo do antilogaritmo do coeficiente $\beta_{1}$, subtraído de 1 (um) para obter a taxa média de crescimento $r$ da série, apresentado pelas equações $6 \mathrm{e}$ 7 e orientações metodológicas contidas em Santana (2003):

$r=\left[\left(e^{\beta}\right)-1\right] \times 100$

$r=\left[\left(2,718281828459045235360287^{\beta}\right)-1\right] \times 100$

O teste $\mathrm{t}$ foi utilizado para analisar o parâmetro $\beta_{1}$ da regressão. Como critério de significância estatística do resultado econométrico, adotou-se o nível de probabilidade de $5 \%$.

\section{Resultados e Discussões}

Nos últimos anos, o agronegócio vem se consolidando como um dos principais segmentos da economia brasileira (GASQUES, 2004). Sua importância resulta da capacidade de gerar riquezas, mesmo em períodos de turbulência econômica.

Atualmente, o agronegócio do brasileiro é destaque internacional nas exportações de soja (grão, farelo e óleo), carnes, café, açúcar, milho e algodão. 
3.1 A importância do agronegócio para as economias brasileira e do Rio Grande do Sul

A diversificação das atividades e o nível de produção nos diferentes elos das cadeias produtivas contribuiu para que o agronegócio se tornasse responsável por cerca de 21,35\% do PIB do Brasil (CEPEA, 2017). A capacidade de gerar bons resultados, mesmo em períodos de crises econômicas, tem sido o marco do setor que, mesmo na presença de gargalos logísticos, segue em franca expansão.

A importância do segmento é verificada, ainda, pelos sucessivos superávits na Balança Comercial brasileira, onde são registrados os saldos das exportações e importações de mercadorias. Historicamente, o setor foi responsável, em média, por 40,6\% das exportações totais, o que coloca o agro em condição de destaque no comércio exterior nacional. Neste contexto, destaca-se que apenas nos anos de 2005 e 2006 o saldo comercial do conjunto do comércio exterior brasileiro foi superior ao do agronegócio (BRASIL, 2018a; 2018b).

No Rio Grande do Sul, da média de US\$12,92 bilhões exportados anualmente pelo estado, cerca de US\$ 7,97 foram exportações do agronegócio, em especial do complexo soja (grão, farelo e óleo), do complexo carnes (bovina, de frango, pato, peru, suína e equina), fumo e seus produtos, produtos alimentícios diversos, entre outros (BRASIL, 2018a; 2018b). Neste sentido, observa-se que nos últimos 21 anos, em seu pior desempenho, o agronegócio foi responsável por 52\% das exportações estaduais.

Por outro lado, o Rio Grande do Sul importa cereais, farinhas e preparações, lácteos, produtos hortícolas, leguminosas, raízes e tubérculos, produtos oleaginosos (exceto soja), bebidas alcoólicas, não alcoólicas e preparações. Porém, o volume importado pelo agro, que em 2017 foi de US\$ 747 milhões, é inferior ao volume exportado, que no mesmo período foi de US\$11,57 bilhões (BRASIL, 2018).

Por se tratar de um segmento competitivo, o superávit do agronegócio gaúcho foi superior ao superávit do conjunto da economia nos últimos 21 anos. Em âmbito nacional, o Rio Grande do Sul se constituiu como o quarto maior exportador do agronegócio em 2017, com exportações na casa dos US\$ 11,57 bilhões e 12,06\% do total nacional. As exportações do complexo soja (grão, farelo e óleo) ajudam a explicar parte significativa deste desempenho, uma vez que já chegaram a responder por 48\% das exportações do agronegócio gaúcho (em 2014) e atualmente representam 47,3\% do total (BRASIL, 2018a; 2018b).

Portanto, são as exportações do complexo soja, associadas à demanda interna por grão, farelo e óleo de soja, que se constituem como a base para a expansão da lavoura de soja no Brasil e no Rio Grande do Sul. Este desempenho, associado ao crédito, inovações tecnológicas e conjuntos de insumos que garantiram o aumento da produtividade das lavouras nos últimos anos, estimulou os produtores rurais a expandir a lavoura de soja em regiões que não tinham esta tradição, principalmente no Sudeste e Centro Ocidental Rio-grandense.

Atualmente, no estado do Rio Grande do Sul também existem regiões de fronteira agrícola para a soja e foi justamente a partir do incremento destas que se viabilizou o crescimento de $87 \%$ da área plantada entre 2000 e 2017 . Neste processo de avanço, muitas áreas até então utilizadas para os cultivos de arroz e pecuária 
cederam espaço para a oleaginosa, tradicionalmente cultivada no Noroeste Riograndense.

O elevado crescimento relativo da área plantada de soja em regiões que até o ano de 2000 não eram consideradas tradicionais, a exemplo das Mesorregiões Centro Ocidental, Centro Oriental, Sudeste, Sudoeste e Nordeste Rio-grandense, foi responsável por agregar cerca de 2,65 milhões de hectares de cultivo apenas no RS, conforme é possível observar na Figura 1.

Figura 1. Área Plantada de Soja no Rio Grande do Sul: ano-safra 2000/2001 a $2017 / 2018$

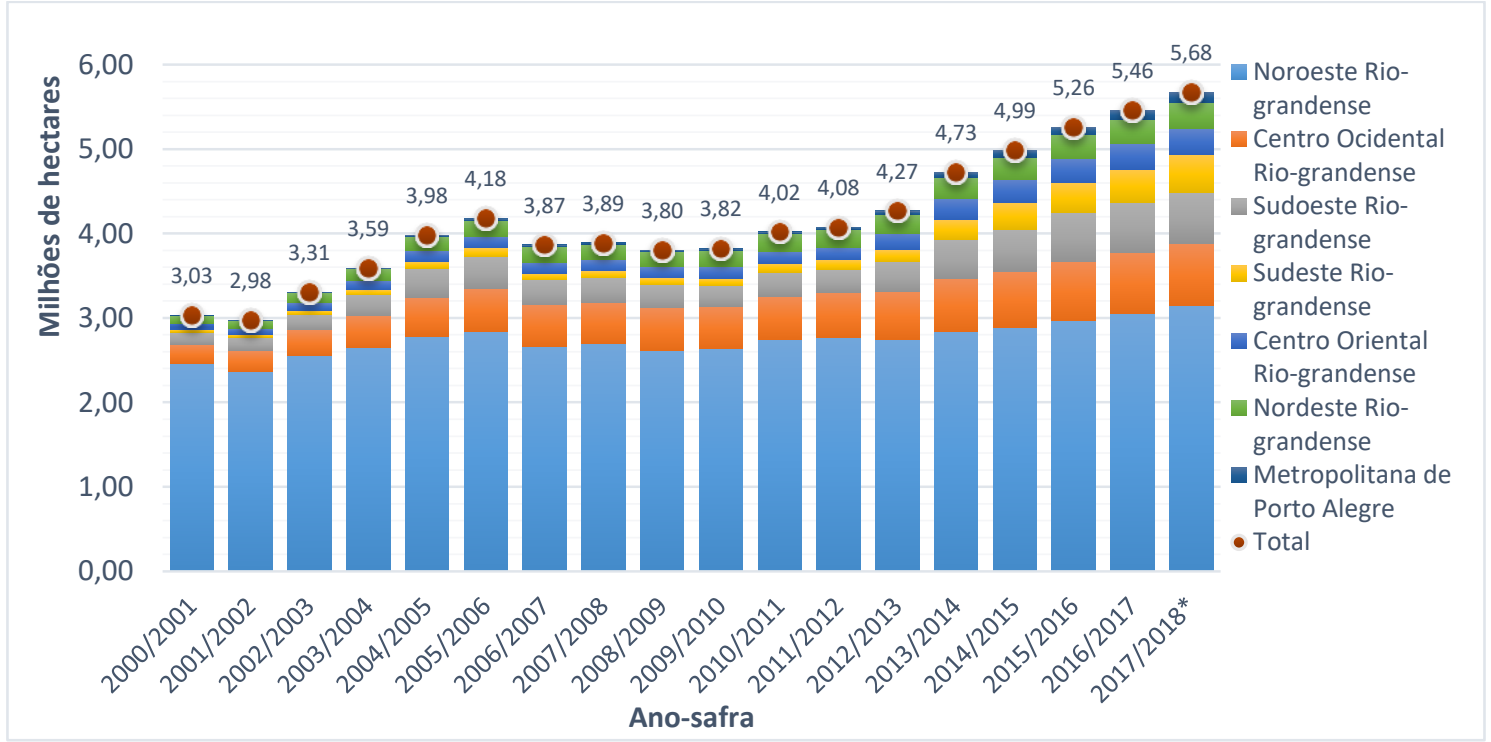

Fonte: IBGE (2018).

Atualmente, estas atividades de cultivo são responsáveis por fomentar diversos segmentos de indústrias responsáveis por fornecer insumos e uma extensa rede de empresas e cooperativas que comercializam sementes, defensivos e fertilizantes, entre outros.

\subsection{Os custos médios de produção de soja no Rio Grande do Sul}

A o longo dos últimos 20 anos, a constante adoção de novas tecnologias, derivadas da busca por maior produtividade, pelos produtores rurais, resultou em mudanças na estrutura dos custos médios de produção de soja.

Comparativamente, neste período, os custos com sementes cresceram 101\%; os custos com fertilizantes aumentaram 38\% e; o aumento de custos com defensivos foi de $46 \%$.

Isto fez com que o custo médio por hectare cultivado, na safra 2017/2018 chegasse ao nível de $\mathrm{R} \$ 250,00$ com sementes, $\mathrm{R} \$ 447,76$ com fertilizantes e $\mathrm{R} \$$ 449,22 com defensivos (Tabela 1). 
Tabela 1. Custos médios de produção soja (em R\$/ha) com sementes, fertilizantes e defensivos: Rio Grande do Sul, safras 2000/2001 a 2017/2018

\begin{tabular}{|c|c|c|c|c|c|c|c|}
\hline \multirow[b]{2}{*}{ Safra } & \multicolumn{3}{|c|}{ VALORES NOMINAIS (R\$/ha) } & \multirow[b]{2}{*}{ IGP-DI } & \multicolumn{3}{|c|}{ VALORES REAIS (R\$/ha) } \\
\hline & $\begin{array}{l}\text { Semen- } \\
\text { tes }\end{array}$ & $\begin{array}{c}\text { Fertilizan } \\
\text {-tes }\end{array}$ & $\begin{array}{l}\text { Defen- } \\
\text { sivos }\end{array}$ & & $\begin{array}{l}\text { Semen- } \\
\text { tes }\end{array}$ & $\begin{array}{c}\text { Fertilizan } \\
\text {-tes }\end{array}$ & $\begin{array}{l}\text { Defensi- } \\
\text { vos }\end{array}$ \\
\hline $2000 / 2001$ & 35,75 & 93,00 & 88,24 & 28,71 & 124,54 & 323,97 & 307,39 \\
\hline $2001 / 2002$ & 36,40 & 79,20 & 79,99 & 31,68 & 114,90 & 249,99 & 252,49 \\
\hline $2002 / 2003$ & 47,45 & 86,00 & 88,37 & 35,96 & 131,95 & 239,16 & 245,75 \\
\hline $2003 / 2004$ & 98,15 & 139,00 & 109,60 & 44,16 & 222,27 & 314,79 & 248,20 \\
\hline $2004 / 2005$ & 92,95 & 159,55 & 133,51 & 48,31 & 192,41 & 330,27 & 276,37 \\
\hline $2005 / 2006$ & 133,90 & 127,53 & 140,26 & 51,19 & 261,57 & 249,13 & 274,00 \\
\hline 2006/2007 & 58,50 & 118,10 & 232,47 & 52,07 & 112,34 & 226,79 & 446,43 \\
\hline $2007 / 2008$ & 48,75 & 131,66 & 172,22 & 54,72 & 89,09 & 240,61 & 314,73 \\
\hline 2008/2009 & 100,00 & 364,94 & 185,25 & 60,87 & 164,30 & 599,58 & 304,36 \\
\hline $2009 / 2010$ & 107,27 & 279,70 & 185,91 & 61,96 & 173,14 & 451,45 & 300,07 \\
\hline $2010 / 2011$ & 82,02 & 197,15 & 139,42 & 65,41 & 125,39 & 301,40 & 213,14 \\
\hline $2011 / 2012$ & 96,48 & 184,68 & 167,20 & 70,99 & 135,91 & 260,16 & 235,54 \\
\hline $2012 / 2013$ & 132,25 & 242,82 & 169,44 & 75,23 & 175,79 & 322,77 & 225,23 \\
\hline $2013 / 2014$ & 100,00 & 633,59 & 313,12 & 79,81 & 125,31 & 793,92 & 392,36 \\
\hline $2014 / 2015$ & 175,00 & 402,65 & 338,82 & 84,08 & 208,13 & 478,87 & 402,96 \\
\hline $2015 / 2016$ & 259,00 & 488,35 & 415,28 & 89,89 & 288,14 & 543,30 & 462,01 \\
\hline $2016 / 2017$ & 237,50 & 494,61 & 430,18 & 99,05 & 239,79 & 499,37 & 434,32 \\
\hline $2017 / 2018$ & 250,00 & 447,76 & 449,22 & 100,00 & 250,00 & 447,76 & 449,22 \\
\hline
\end{tabular}

Fonte: Elaboração própria com base em Brasil (2018c) e Brasil (2018d).

As equações 7, 8 e 9 mostram que a tendência de elevação dos custos é crescente, tanto para sementes (CtSementes), quanto para fertilizantes (CtFertilizantes) e defensivos (CtDefensivos). Também, observa-se que a média de crescimento anual do períodos foi de $2,90 \%$ de elevação nos custos com sementes, $4,43 \%$ de elevação nos custos dos fertilizantes e $2,66 \%$ de aumento nos custos com defensivos.

$$
\begin{aligned}
& \frac{{\text { ln } \text { CtSementes }_{i}=4,8337+0,0286 t}_{i}}{\left.R^{2}=0,1995 ; F_{(1,17} \mathrm{gl}\right)=3,9878} ; r=\left[\left(e^{0,0286}\right)-1\right] \times 100=2,90 \% \\
& \frac{\text { In CtFertilizantes }_{i}=5,4652+0,0433 t_{i}}{\left.R^{2}=0,3883 ; F_{(1,17} g l\right)} ;=10,1586=\left[\left(e^{0,0433}\right)-1\right] \times 100=4,43 \% \\
& \frac{\text { ln CtDefensivos }_{i}=5,4896+0,0263 t}{i} ; r=\left[\left(e^{0,0263}\right)-1\right] \times 100=2,66 \%
\end{aligned}
$$

Por outro lado, verificou-se aumento na produtividade média das lavouras, que passou de $3.082 \mathrm{~kg} / \mathrm{ha}$ para $3.835 \mathrm{~kg} / \mathrm{ha}$ (BRASIL, 2017). Neste processo, os novos insumos para a realização de tratos culturais, incluindo máquinas mais eficientes, crédito, fertilizantes, defensivos, entre outros, consolidou a existência de uma extensa rede de empresas e cooperativas que atuam no mercado varejista de insumos agrícolas.

Estas, por sua vez, possuem papel fundamental para as atividades do setor, pois além gerar empregos, impostos e se constituir como o canal de 
comercialização, se constituem como importantes atores das economias municipais.

3.3 Volume de negócios da lavoura de soja no Rio Grande do Sul

Com o objetivo de mensurar o volume de negócios no mercado varejista de sementes, fertilizantes e defensivos para a lavoura de soja, estimou-se os custos totais dos sojicultores gaúchos com estes insumos.

A estimativa foi realizada através da equação 1 , apresentada no item 3.2 desta pesquisa, em que se verifica a multiplicação simples do custo médio/ha pela área plantada de soja do respectivo período.

$\mathrm{Na}$ Tabela 2, apresentou-se o $V k_{\text {tsementes }}$, valor econômico das sementes utilizadas nas lavouras de soja do Rio Grande do Sul no período 2000-2015.

Tabela 2. Volume investido pelos agricultores ( $R \$$ milhões de 2017) em sementes na produção de soja no Rio Grande do Sul: ano-safra 2000/2001 a 2017/2018

\begin{tabular}{|c|c|c|c|c|c|c|c|c|}
\hline Safra & $\begin{array}{l}\text { Noro- } \\
\text { este }\end{array}$ & $\begin{array}{l}\text { Centro } \\
\text { Ocidental }\end{array}$ & $\begin{array}{l}\text { Sudo- } \\
\text { este }\end{array}$ & $\begin{array}{l}\text { Sude- } \\
\text { ste }\end{array}$ & $\begin{array}{l}\text { Centro } \\
\text { Oriental }\end{array}$ & $\begin{array}{l}\text { Nor- } \\
\text { deste }\end{array}$ & $\begin{array}{l}\text { Metro- } \\
\text { politana }\end{array}$ & Total \\
\hline $2000 / 2001$ & 306,73 & 28,34 & 17,83 & 4,36 & 8,05 & 11,80 & 0,30 & 377,41 \\
\hline $2001 / 2002$ & 271,84 & 29,12 & 17,62 & 4,23 & 8,25 & 10,34 & 0,59 & 341,99 \\
\hline $2002 / 2003$ & 337,47 & 40,04 & 24,05 & 6,78 & 11,18 & 15,86 & 1,02 & 436,41 \\
\hline $2003 / 2004$ & 588,62 & 84,43 & 55,37 & 13,85 & 23,84 & 30,14 & 2,16 & 798,40 \\
\hline $2004 / 2005$ & 535,73 & 87,92 & 66,90 & 15,79 & 24,83 & 31,49 & 3,96 & 766,62 \\
\hline $2005 / 2006$ & 742,03 & 133,75 & 98,66 & 28,40 & 35,76 & 48,12 & 6,46 & $1.093,18$ \\
\hline $2006 / 2007$ & 298,71 & 55,93 & 33,54 & 8,84 & 14,68 & 20,48 & 2,41 & 434,59 \\
\hline $2007 / 2008$ & 240,04 & 43,48 & 26,22 & 7,45 & 11,47 & 16,20 & 1,78 & 346,64 \\
\hline $2008 / 2009$ & 430,82 & 81,94 & 45,27 & 13,19 & 21,39 & 29,44 & 3,00 & 625,05 \\
\hline $2009 / 2010$ & 457,09 & 86,29 & 42,40 & 15,70 & 23,58 & 33,70 & 3,20 & 661,95 \\
\hline $2010 / 2011$ & 344,56 & 64,19 & 35,13 & 14,01 & 17,44 & 26,61 & 2,35 & 504,29 \\
\hline $2011 / 2012$ & 376,80 & 72,31 & 36,17 & 16,85 & 20,05 & 28,82 & 2,91 & 553,90 \\
\hline $2012 / 2013$ & 483,01 & 99,16 & 62,31 & 25,56 & 34,47 & 38,44 & 7,56 & 750,51 \\
\hline $2013 / 2014$ & 355,72 & 78,50 & 58,05 & 30,08 & 31,83 & 30,05 & 8,19 & 592,42 \\
\hline $2014 / 2015$ & 601,99 & 138,46 & 103,19 & 65,55 & 57,55 & 54,34 & 17,47 & $1.038,56$ \\
\hline $2015 / 2016$ & 855,40 & 201,19 & 168,49 & 102,07 & 82,76 & 80,26 & 26,58 & $1.516,75$ \\
\hline $2016 / 2017$ & 732,79 & 172,05 & 143,02 & 95,08 & 71,61 & 69,98 & 25,69 & $1.310,22$ \\
\hline $2017 / 2018$ & 786,47 & 184,34 & 152,09 & 110,97 & 77,63 & 76,44 & 31,11 & $1.419,04$ \\
\hline Média & 485,88 & 93,41 & 65,91 & 32,15 & 32,02 & 36,25 & 8,15 & 753,77 \\
\hline Mediana & 443,95 & 83,18 & 50,32 & 15,74 & 23,71 & 30,10 & 3,10 & 643,50 \\
\hline Desv. Pad. & 186,80 & 50,93 & 46,17 & 34,47 & 23,39 & 20,81 & 9,64 & 362,52 \\
\hline Máximo & 855,40 & 201,19 & 168,49 & 110,97 & 82,76 & 80,26 & 31,11 & $1.516,75$ \\
\hline Mínimo & 240,04 & 28,34 & 17,62 & 4,23 & 8,05 & 10,34 & 0,30 & 341,99 \\
\hline
\end{tabular}

Fonte: Elaboração própria com base em Brasil (2018c) e Brasil (2018d). 
Constatou-se que o volume de negócios do segmento, no ano-safra 20172018, foi de aproximadamente $\mathrm{R} \$ 1,42$ bilhão. A mesorregião Noroeste Rio Grandense concentra a maior fração deste montante, mas o volume de negócios nas demais mesorregiões cresceu significativamente no período analisado.

Parte do crescimento pode ser explicado pela expansão da área plantada, mas também está associado aos avanços da biotecnologia, em especial, pela introdução da tecnologia Roundup Ready ${ }^{\circledR}$ e Roundup Ready $2^{\circledR}{ }^{\circledR}$. Neste sentido, 0 cultivo da soja transgênica passou a englobar a totalidade das lavouras gaúchas e as campanhas de conscientização sobre a importância da qualidade e da origem das sementes, bem como a capacidade sistêmica de identificar e cobrar altas taxas de produtores que utilizam sementes piratas, contribuíram para o aumento na utilização de sementes adquiridas em detrimento das sementes salvas2.

Neste segmento, em específico, o desenvolvimento de variedades adaptadas às condições edafoclimáticas de regiões específicas e com maior índice de produtividade deve ser destacado. A mais nova introdução da biotecnologia em sementes, através da Soja BT resistente a lagarta, iniciada a partir da safra de 2015, tem contribuído para a utilização de sementes certificadas.

Para Costa e Santana (2013), o mercado de sementes transgênicas é dominado pelas empresas norte americanas Monsanto do Brasil Ltda. e DuPont do Brasil S/A. "Mesmo a Embrapa, a Agência Goiana de Desenvolvimento Rural e Fundiário - Agência Rural e FTS Sementes S/A. mantêm convênios para a utilização da tecnologia Roundup Ready ${ }^{\circledR}$, o que significa que o material genético é de propriedade da Monsanto do Brasil Ltda." (COSTA; SANTANA, 2013, p. 64)3.

As maiores taxas anuais de crescimento $(r)$ nos volumes de negócios foram verificadas nas mesorregiões Sudoeste Rio-grandense (18,49\% ao ano) e Metropolitana de Porto Alegre (24,30\% ao ano), mas a tendência de crescimento é uma realidade em todas a mesorregiões gaúchas, conforme pode ser verificado nas equações 10 a 16.

\footnotetext{
Noroeste Riograndense

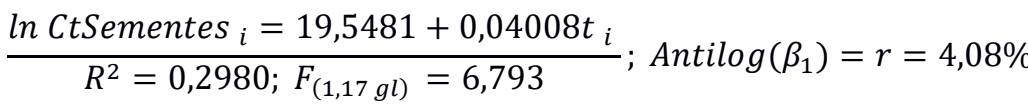

Centro Ocidental Rio-grandense$$
\frac{\ln \text { CtSementes }_{i}=17,3711+0,08699 t_{i}}{R^{2}=0,6215 ; F_{(1,17 g l)}=26,276} ; \operatorname{Antilog}\left(\beta_{1}\right)=r=9,09 \%
$$

Sudoeste Riograndense

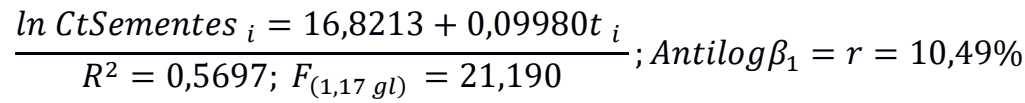

Sudeste Riograndense$$
\frac{\ln \text { CtSementes }_{i}=15,1630+0,169661 t_{i}}{R^{2}=0,780 ; F_{(1,17 \mathrm{gl})}=56,737} ; \operatorname{Antilog}\left(\beta_{1}\right)=r=18,5 \%
$$

${ }^{1}$ Esta tecnologia resultou em sementes geneticamente modificadas, tolerantes ao herbicida à base de glifosato, usado para dessecação pré e pós-plantio.

${ }^{2}$ Semente salva é a semente produzida e armazenada pelo produtor rural.

${ }^{3}$ Anunciada em 2016, a Bayer concluiu a compra da Monsanto em junho de 2018 por US\$ 63 bilhões, criando a maior companhia integrada de pesticidas e sementes do mundo.
} 
Centro-Oriental

Rio-grandense

Nordeste Rio-

grandense

Metropolitana de

Porto Alegre

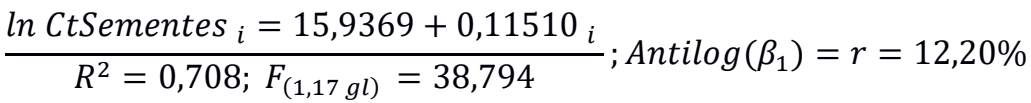

$$
\begin{aligned}
& \frac{{\text { ln } \text { CtSementes }_{i}=16,3650+0,09222}_{i}}{R^{2}=0,669 ; F_{(1,17 \mathrm{gl})}=32,339} ; \operatorname{Antilog}\left(\beta_{1}\right)=r=9,66 \% \\
& \frac{\ln _{\text {CtSementes }} \text { Se }_{i} 13,1308+0,2175_{i}}{R^{2}=0,798 ; F_{(1,17 \mathrm{gl})}=63,114} ; \operatorname{Antilog}\left(\beta_{1}\right)=r=24,30 \%
\end{aligned}
$$

Neste segmento, também se destacam as participações da Syngenta (Suíça), Basf (Alemanha), Bayer (Alemanha) e Dow AgroSciences (EUA). Segundo Thuswohl (2013), estas empresas, juntamente com Monsanto e DuPont, controlam 59,8\% do mercado mundial de sementes comerciais e $76,1 \%$ do mercado de defensivos agrícolas, além de serem responsáveis por $76 \%$ do investimento neste setor.

$\mathrm{Na}$ Tabela 3, apresentou-se o $V k_{\text {tfertilizantes, }}$ valor econômico dos fertilizantes utilizados na lavoura de soja.

Tabela 3. Volume investido pelos agricultores ( $R \$$ milhões de 2017) em fertilizantes

\begin{tabular}{|c|c|c|c|c|c|c|c|c|}
\hline Safra & $\begin{array}{c}\text { Noroes- } \\
\text { te }\end{array}$ & $\begin{array}{c}\text { Centro } \\
\text { Ocidental }\end{array}$ & $\begin{array}{l}\text { Sudo- } \\
\text { este }\end{array}$ & $\begin{array}{l}\text { Sude- } \\
\text { ste }\end{array}$ & $\begin{array}{l}\text { Centro } \\
\text { Oriental }\end{array}$ & $\begin{array}{l}\text { Nor- } \\
\text { deste }\end{array}$ & $\begin{array}{c}\text { Metro- } \\
\text { politana }\end{array}$ & Total \\
\hline 2000/2001 & 797,92 & 73,73 & 46,38 & 11,35 & 20,95 & 30,70 & 0,77 & 981,80 \\
\hline $2001 / 2002$ & 591,48 & 63,37 & 38,33 & 9,21 & 17,95 & 22,49 & 1,27 & 744,10 \\
\hline $2002 / 2003$ & 611,64 & 72,58 & 43,59 & 12,30 & 20,27 & 28,74 & 1,85 & 790,96 \\
\hline $2003 / 2004$ & 833,61 & 119,56 & 78,41 & 19,61 & 33,76 & 42,68 & 3,06 & $1.130,70$ \\
\hline $2004 / 2005$ & 919,58 & 150,92 & 114,84 & 27,10 & 42,62 & 54,06 & 6,80 & $1.315,91$ \\
\hline $2005 / 2006$ & 706,73 & 127,39 & 93,96 & 27,05 & 34,06 & 45,84 & 6,15 & $1.041,17$ \\
\hline $2006 / 2007$ & 603,04 & 112,91 & 67,72 & 17,84 & 29,64 & 41,35 & 4,86 & 877,35 \\
\hline $2007 / 2008$ & 648,29 & 117,43 & 70,82 & 20,12 & 30,97 & 43,74 & 4,82 & 936,18 \\
\hline $2008 / 2009$ & $1.572,24$ & 299,03 & 165,23 & 48,13 & 78,05 & 107,44 & 10,94 & $2.281,06$ \\
\hline $2009 / 2010$ & $1.191,82$ & 225,00 & 110,55 & 40,94 & 61,47 & 87,88 & 8,34 & $1.726,00$ \\
\hline $2010 / 2011$ & 828,21 & 154,28 & 84,45 & 33,68 & 41,93 & 63,96 & 5,65 & $1.212,16$ \\
\hline $2011 / 2012$ & 721,25 & 138,41 & 69,23 & 32,25 & 38,38 & 55,17 & 5,57 & $1.060,27$ \\
\hline $2012 / 2013$ & 886,85 & 182,07 & 114,41 & 46,93 & 63,29 & 70,57 & 13,88 & $1.377,99$ \\
\hline $2013 / 2014$ & $2.253,82$ & 497,39 & 367,78 & 190,57 & 201,64 & 190,41 & 51,91 & $3.753,52$ \\
\hline $2014 / 2015$ & $1.385,09$ & 318,59 & 237,42 & 150,82 & 132,42 & 125,03 & 40,21 & $2.389,57$ \\
\hline $2015 / 2016$ & $1.612,87$ & 379,34 & 317,69 & 192,46 & 156,05 & 151,33 & 50,11 & $2.859,86$ \\
\hline $2016 / 2017$ & $1.526,08$ & 358,31 & 297,84 & 198,02 & 149,13 & 145,73 & 53,50 & $2.728,62$ \\
\hline $2017 / 2018$ & $1.408,59$ & 330,16 & 272,40 & 198,75 & 139,03 & 136,90 & 55,72 & $2.541,55$ \\
\hline Média & $1.061,06$ & 206,69 & 143,95 & 70,95 & 71,76 & 80,22 & 18,08 & $1.652,71$ \\
\hline Mediana & 860,23 & 152,60 & 102,26 & 32,96 & 42,27 & 59,57 & 6,48 & $1.264,04$ \\
\hline Desv. Pad. & 454,41 & 122,91 & 102,83 & 72,84 & 55,61 & 48,90 & 20,41 & 858,77 \\
\hline Máximo & $2.253,82$ & 497,39 & 367,78 & 198,75 & 201,64 & 190,41 & 55,72 & $3 \cdot 753,52$ \\
\hline Mínimo & 591,48 & 63,37 & 38,33 & 9,21 & 17,95 & 22,49 & 0,77 & 744,10 \\
\hline
\end{tabular}
na produção de soja no Rio Grande do Sul: ano-safra 2000/2001 a 2017/2018

Fonte: Elaboração própria com base em Brasil (2018c) e Brasil (2018d). 
O volume de negócios com fertilizantes cresceu consideravelmente a partir de 2000 e alcançou R\$2,541 bilhões no ano-safra 2017/2018.

A distribuição destes negócios, nas mesorregiões gaúchas, ocorre de acordo com a área plantada. Com participação percentual de 55,42\% no ano-safra 2017/2018, o destaque do segmento continua sendo a mesorregião Noroeste Colonial, que chegou a investir cerca de $\mathrm{R} \$ 2,541$ bilhões. Por outro lado, destaca-se 0 crescimento das mesorregiões Sudeste, Sudoeste e Centro Ocidental Riograndense.

Identificou-se que a tendência de crescimento e intensificação da atividade sojícola é crescente em todas as mesorregiões analisadas. Entre as mesorregiões que apresentaram maior taxa de crescimento, destacam-se a metropolitana de Porto Alegre (26,14\% ao ano) e a Sudeste Rio-grandense (20,24\% ao ano), conforme é possível observar nas equações 17 a 23.

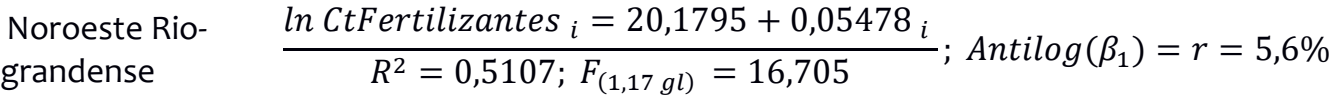

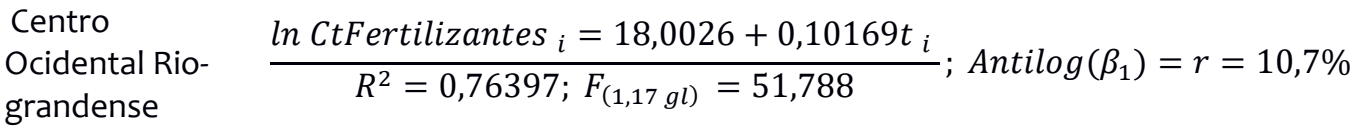

$$
\begin{aligned}
& \begin{array}{ll}
\text { Sudoeste Rio- } \\
\text { grandense }
\end{array} \frac{\text { In CtFertilizantes }_{i}=17,4527+0,11450 t_{i}}{R^{2}=0,729 ; F_{(1,17 g l)}=43,037} ; \operatorname{Antilog}\left(\beta_{1}\right)=r=12,1 \%
\end{aligned}
$$

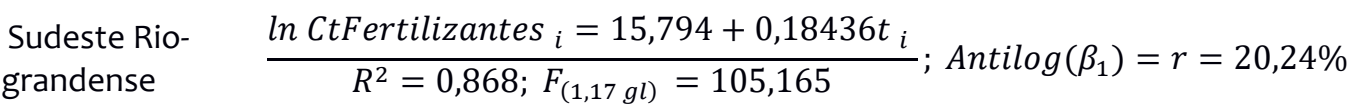

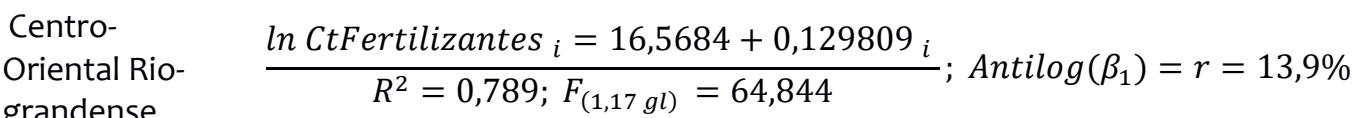

$$
\begin{aligned}
& \text { grandense } \\
& \begin{array}{ll}
\text { Nordeste Rio- } & \frac{\text { ln CtFertilizantes }_{i}=16,9965+0,106917}{i} \\
\text { grandense } & R^{2}=0,80 ; F_{(1,17 \mathrm{gl})}=64,021
\end{array} \operatorname{Antilog}\left(\beta_{1}\right)=r=11,3 \%
\end{aligned}
$$

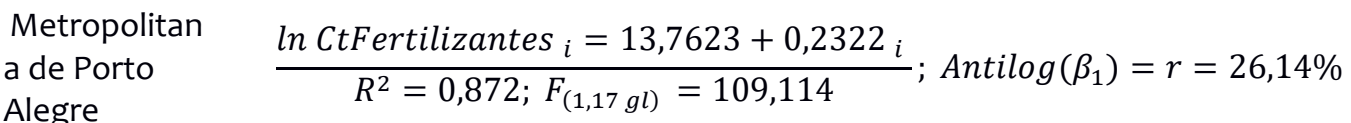

Pelo fato de o mercado nacional importar a maior parte dos fertilizantes utilizados nos cultivos de soja (COSTA; SANTANA, 2014), os preços domésticos sofrem influência da matéria-prima importada (BERALDO; FIGUEIREDO, 2016). Neste contexto, observa-se que a desvalorização do real ocasionou significativo aumento nos custos com os fertilizantes, mas por se tratar de insumo essencial, os produtores priorizam o investimento neste insumo.

$\mathrm{Na}$ Tabela 4, apresentou-se o $V k_{\text {tdefensivos }}$, valor econômico dos defensivos utilizados nas lavouras de soja do Rio Grande do Sul no período 2000-2015. 
Tabela 4. Volume investido pelos agricultores ( $R \$$ milhões de 2017) em defensivos na produção de soja no Rio Grande do Sul: ano-safra 2000/2001 a 2017/2018

\begin{tabular}{|ccccccccc}
\hline Safra & $\begin{array}{c}\text { Noro- } \\
\text { este }\end{array}$ & $\begin{array}{c}\text { Centro } \\
\text { Ocidental }\end{array}$ & $\begin{array}{c}\text { Sudo- } \\
\text { este }\end{array}$ & $\begin{array}{c}\text { Sudes- } \\
\text { te }\end{array}$ & $\begin{array}{c}\text { Centro } \\
\text { Oriental }\end{array}$ & $\begin{array}{c}\text { Nor- } \\
\text { deste }\end{array}$ & $\begin{array}{c}\text { Metro- } \\
\text { politana }\end{array}$ & Total \\
\hline $2000 / 2001$ & 757,08 & 69,95 & 44,01 & 10,77 & 19,88 & 29,12 & 0,73 & 931,55 \\
\hline $2001 / 2002$ & 597,38 & 64,00 & 38,71 & 9,30 & 18,13 & 22,71 & 1,29 & 751,52 \\
\hline $2002 / 2003$ & 628,50 & 74,58 & 44,79 & 12,63 & 20,83 & 29,53 & 1,90 & 812,76 \\
\hline $2003 / 2004$ & 657,29 & 94,28 & 61,83 & 15,47 & 26,62 & 33,65 & 2,41 & 891,54 \\
\hline $2004 / 2005$ & 769,50 & 126,29 & 96,09 & 22,67 & 35,66 & 45,24 & 5,69 & $1.101,14$ \\
\hline $2005 / 2006$ & 777,27 & 140,11 & 103,34 & 29,75 & 37,46 & 50,41 & 6,76 & $1.145,10$ \\
\hline $2006 / 2007$ & $1.187,04$ & 222,25 & 133,29 & 35,12 & 58,35 & 81,39 & 9,56 & $1.727,00$ \\
\hline $2007 / 2008$ & 848,00 & 153,61 & 92,64 & 26,32 & 40,50 & 57,21 & 6,30 & $1.224,59$ \\
\hline $2008 / 2009$ & 798,10 & 151,80 & 83,87 & 24,43 & 39,62 & 54,54 & 5,55 & $1.157,91$ \\
\hline $2009 / 2010$ & 792,18 & 149,55 & 73,48 & 27,21 & 40,86 & 58,41 & 5,54 & $1.147,23$ \\
\hline $2010 / 2011$ & 585,69 & 109,11 & 59,72 & 23,82 & 29,65 & 45,23 & 4,00 & 857,21 \\
\hline $2011 / 2012$ & 652,99 & 125,31 & 62,68 & 29,20 & 34,75 & 49,95 & 5,04 & 959,91 \\
\hline $2012 / 2013$ & 618,84 & 127,05 & 79,83 & 32,75 & 44,17 & 49,24 & 9,68 & 961,56 \\
\hline $2013 / 2014$ & $1.113,84$ & 245,81 & 181,75 & 94,18 & 99,65 & 94,10 & 25,65 & $1.854,99$ \\
\hline $2014 / 2015$ & $1.165,52$ & 268,08 & 199,79 & 126,91 & 111,42 & 105,21 & 33,83 & $2.010,77$ \\
\hline $2015 / 2016$ & $1.371,54$ & 322,58 & 270,16 & 163,66 & 132,70 & 128,69 & 42,61 & $2.431,95$ \\
\hline $2016 / 2017$ & $1.327,28$ & 311,64 & 259,05 & 172,23 & 129,71 & 126,75 & 46,53 & $2.373,18$ \\
\hline $2017 / 2018$ & $1.413,19$ & 331,23 & 273,29 & 199,40 & 139,48 & 137,35 & 55,90 & $2.549,84$ \\
\hline Média & 892,29 & 171,51 & 119,91 & 58,66 & 58,86 & 66,60 & 14,94 & $1.382,76$ \\
\hline Mediana & 784,73 & 144,83 & 88,25 & 28,20 & 40,06 & 52,47 & 6,00 & $1.146,17$ \\
\hline Desv. Pad. & 279,50 & 86,56 & 78,44 & 61,01 & 41,33 & 35,58 & 17,17 & 589,12 \\
\hline Máximo & $1.413,19$ & 331,23 & 273,29 & 199,40 & 139,48 & 137,35 & 55,90 & $2.549,84$ \\
\hline Mínimo & 585,69 & 64,00 & 38,71 & 9,30 & 18,13 & 22,71 & 0,73 & 751,52 \\
\hline
\end{tabular}

Fonte: Elaboração própria com base em Brasil (2018c) e Brasil (2018d).

Ao longo da série analisada, observou-se que o investimento em defensivos agrícolas cresceu consistentemente entre 2000 e 2006. No período 2006 a 2010 observou-se uma tendência de queda, que pode ser explicada pela valorização do Real em relação ao Dólar. Contudo, superada as dificuldades de 2010, momento em muitos produtores deixaram de investir nas últimas aplicações fitossanitárias, os desembolsos com este insumo se elevaram em todas a mesorregiões analisadas.

O volume de negócios gerado pela comercialização de defensivos para a lavoura de soja chegou a R\$2,549 bilhões no ano-safra 2018/2018, ante R\$931,55 milhões no ano de 2000/2001.

A Mesorregião Noroeste Rio-grandense se constitui como o principal mercado, pois respondeu por cerca de $55 \%$ dos gastos totais com estes insumos. Apesar de ter o maior crescimento relativo, a Mesorregião Metropolitana de Porto Alegre se constitui como o mercado menor, uma vez que detém a menor área plantada de soja. Em termos relativos, o maior crescimento foi verificado na Mesorregião Metropolitana de Porto Alegre e Sudeste Rio-grandense, respectivamente com variação percentual de $7557 \%$ e $1751 \%$ no período analisado. Contudo, a tendência de crescimento foi verificada em todas as mesorregiões analisadas, conforme é possível observar nas equações 24 a 31. 


$$
\begin{aligned}
& \begin{array}{ll}
\text { Noroeste Rio- } & \text { ln CtDefensivos } \\
\text { grandense } & \frac{\text { fend }^{2}=20,204+0,03783 t_{i}}{R^{2}=0,4330 ; F_{(1,17 g l)}=12,223} ; \operatorname{Antilog}\left(\beta_{1}\right)=r=3,86 \%
\end{array}
\end{aligned}
$$

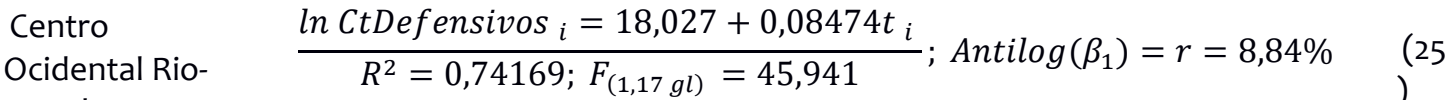

$$
\begin{aligned}
& \text { grandense } \\
& \text { Sudoeste Rio- } \\
& \text { grandense }
\end{aligned}
$$

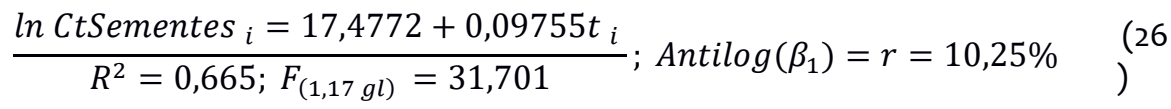

$$
\begin{aligned}
& \text { Sudeste Rio- } \\
& \text { grandense }
\end{aligned}
$$

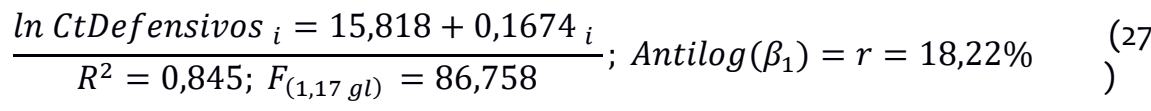

$$
\begin{aligned}
& \text { Centro- } \\
& \text { Oriental Rio- } \\
& \text { grandense } \\
& \frac{{\ln C t D \text { ensivos }_{i}=16,5928+0,1129}_{i}}{R^{2}=0,789 ; F_{(1,17 \mathrm{gl})}=64,844} ; \operatorname{Antilog}\left(\beta_{1}\right)=r=11,95 \% \\
& \text { Nordeste Rio- } \\
& \text { grandense }
\end{aligned}
$$

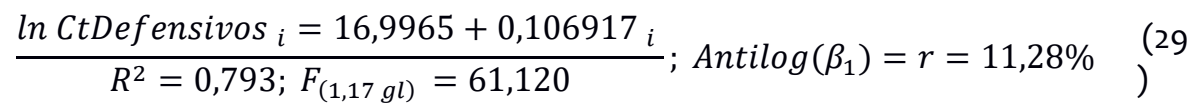

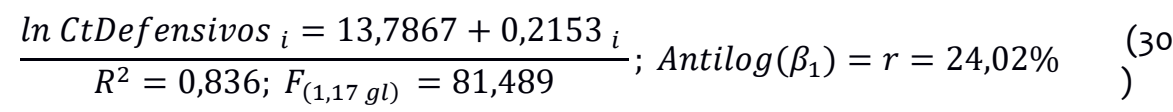

$$
\begin{aligned}
& \frac{\operatorname{lnCtDefensivos}_{i}=20,4063+0,0588_{i}}{R^{2}=0,598 ; F_{(1,17 \mathrm{gl})}=23,800} ; \operatorname{Antilog}\left(\beta_{1}\right)=r=6,06 \%
\end{aligned}
$$

Em boa medida, o surgimento e intensificação de pragas como a Ferrugem Asiática (Phakopsora pachyrhizi), com elevado potencial para reduzir a produtividade das lavouras e o aumento da área plantada podem explicar o crescimento médio deste mercado. Também se encontram explicações no desenvolvimento de novos produtos, que entraram no mercado em substituição aos antigos, e na perda de eficiência dos antigos, que pode ser explicada pela capacidade de adaptação de fungos, que ao longo do tempo se tornam resistentes.

No agregado, observa-se que o volume de negócios de sementes, fertilizantes e defensivos passou de $R \$ 2,29$ bilhões para $R \$ 6,51$ bilhões entre os anos safra 2000/2001 e 2018/2018. Também, destaca-se que a partir do ano-safra 2013/2014, os custos de produção com estes insumos passaram a ser significativamente maiores (Figura 2). 
Figura 2. Volume investido ( $\mathrm{R} \$$ bilhões de 2017) em sementes, fertilizantes e defensivos na produção de soja do Rio Grande do Sul: ano-safra 2000/2001 a $2017 / 2018$

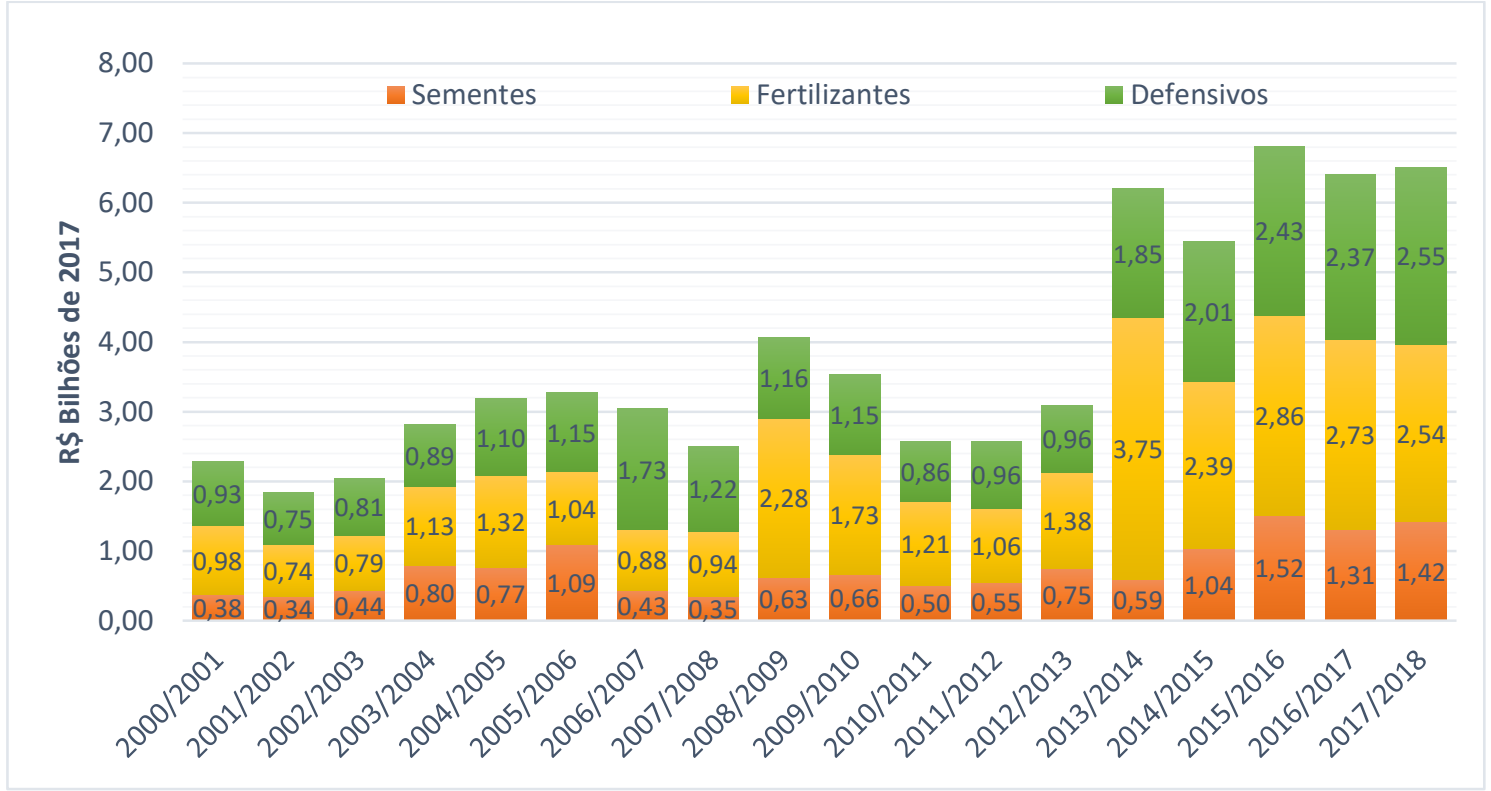

Fonte: Elaboração própria com base em Brasil (2018c) e Brasil (2018d).

Tanto no segmento de sementes, quanto nos segmentos de fertilizantes e defensivos, foram verificados crescimento. Condições específicas, que vão desde a taxa de câmbio a estiagens interferem nos custos com os insumos analisados e, por consequência, existem períodos que mostram redução em relação ao ano anterior, mas, em média, a tendência é de crescimento.

Neste mercado, ao constatar que a relação custo/benefício é favorável, o sojicultor tenderá a continuar investindo com vistas a superar os atuais limites de produtividade.

3.4 Margens de comercialização do varejo e faturamento bruto das vendas de sementes, fertilizantes e defensivos

A margem de comercialização do comércio atacadista é um indicador importante, pois equivale ao montante de recursos financeiros apropriados pela rede de cooperativas e empresas que vendem insumos para a lavoura de soja.

Seja pela folha de pagamento ou pelos demais itens de custos fixos e variáveis das empresas e cooperativas que atuam no varejo, o fato é que os recursos apropriados por este segmento tendem a circular, predominantemente, nas economias locais.

No caso do segmento de sementes, a margem média de comercialização apurada pela pesquisa, em entrevistas com empresários do segmento, foi de $12 \%$. Portanto, a simples multiplicação deste coeficiente pelo valor econômico das sementes utilizadas no plantio de soja $\left(V k_{\text {tsementes }}\right)$ permitiu identificar a margem de comercialização do varejo. Os resultados podem ser observados na Tabela 5. 
Tabela 5. Margem de Comercialização (12\%) no comércio de sementes (em R\$ milhões de 2017): ano-safra 2000/2001 a 2017/2018

\begin{tabular}{|c|c|c|c|c|c|c|c|c|}
\hline Safra & $\begin{array}{c}\text { Noroes- } \\
\text { te }\end{array}$ & $\begin{array}{c}\text { Centro } \\
\text { Ocidental }\end{array}$ & $\begin{array}{l}\text { Sudo- } \\
\text { este }\end{array}$ & $\begin{array}{l}\text { Sude- } \\
\text { ste }\end{array}$ & $\begin{array}{l}\text { Centro } \\
\text { Oriental }\end{array}$ & $\begin{array}{c}\text { Nordes- } \\
\text { te }\end{array}$ & $\begin{array}{c}\text { Metro- } \\
\text { politana }\end{array}$ & Total \\
\hline $2000 / 2001$ & 36,81 & 3,40 & 2,14 & 0,52 & 0,97 & 1,42 & 0,04 & 45,29 \\
\hline $2001 / 2002$ & 32,62 & 3,49 & 2,11 & 0,51 & 0,99 & 1,24 & 0,07 & 41,04 \\
\hline $2002 / 2003$ & 40,50 & 4,81 & 2,89 & 0,81 & 1,34 & 1,90 & 0,12 & 52,37 \\
\hline $2003 / 2004$ & 70,63 & 10,13 & 6,64 & 1,66 & 2,86 & 3,62 & 0,26 & 95,81 \\
\hline $2004 / 2005$ & 64,29 & 10,55 & 8,03 & 1,89 & 2,98 & 3,78 & 0,48 & 91,99 \\
\hline $2005 / 2006$ & 89,04 & 16,05 & 11,84 & 3,41 & 4,29 & 5,77 & 0,77 & 131,18 \\
\hline $2006 / 2007$ & 35,85 & 6,71 & 4,03 & 1,06 & 1,76 & 2,46 & 0,29 & 52,15 \\
\hline $2007 / 2008$ & 28,81 & 5,22 & 3,15 & 0,89 & 1,38 & 1,94 & 0,21 & 41,60 \\
\hline $2008 / 2009$ & 51,70 & 9,83 & 5,43 & 1,58 & 2,57 & 3,53 & 0,36 & 75,01 \\
\hline $2009 / 2010$ & 54,85 & 10,36 & 5,09 & 1,88 & 2,83 & 4,04 & 0,38 & 79,43 \\
\hline $2010 / 2011$ & 41,35 & 7,70 & 4,22 & 1,68 & 2,09 & 3,19 & 0,28 & 60,51 \\
\hline 2011/2012 & 45,22 & 8,68 & 4,34 & 2,02 & 2,41 & 3,46 & 0,35 & 66,47 \\
\hline $2012 / 2013$ & 57,96 & 11,90 & 7,48 & 3,07 & 4,14 & 4,61 & 0,91 & 90,06 \\
\hline $2013 / 2014$ & 42,69 & 9,42 & 6,97 & 3,61 & 3,82 & 3,61 & 0,98 & 71,09 \\
\hline $2014 / 2015$ & 72,24 & 16,62 & 12,38 & 7,87 & 6,91 & 6,52 & 2,10 & 124,63 \\
\hline $2015 / 2016$ & 102,65 & 24,14 & 20,22 & 12,25 & 9,93 & 9,63 & 3,19 & 182,01 \\
\hline $2016 / 2017$ & 87,93 & 20,65 & 17,16 & 11,41 & 8,59 & 8,40 & 3,08 & 157,23 \\
\hline $2017 / 2018$ & 94,38 & 22,12 & 18,25 & 13,32 & 9,32 & 9,17 & 3,73 & 170,28 \\
\hline Média & 58,31 & 11,21 & 7,91 & 3,86 & 3,84 & 4,35 & 0,98 & 90,45 \\
\hline Mediana & 53,27 & 9,98 & 6,04 & 1,89 & 2,84 & 3,61 & 0,37 & 77,22 \\
\hline Desv. Pad. & 22,42 & 6,11 & 5,54 & 4,14 & 2,81 & 2,50 & 1,16 & 43,50 \\
\hline Máximo & 102,65 & 24,14 & 20,22 & 13,32 & 9,93 & 9,63 & 3,73 & 182,01 \\
\hline Mínimo & 28,81 & 3,40 & 2,11 & 0,51 & 0,97 & 1,24 & 0,04 & 41,04 \\
\hline
\end{tabular}

Fonte: Elaboração própria com base em Brasil (2018c) e Brasil (2018d).

O primeiro fato a destacar é o crescimento de $\mathrm{R} \$ 45,29 \mathrm{mi}$ para 170,28 mi na margem de comercialização do comércio atacadista $\left(M v_{t}\right)$. Somente no ano-safra 2017/2018, o $M v_{t}$ estimado para o estado alcançou $\mathrm{R} \$ 170,28$ milhões. Este foi o segundo melhor desempenho em toda a série analisada.

Destaca-se que a maior parte do volume de negócios ficou concentrada na Mesorregião Noroeste Rio-Grandense ( $55 \%$ do total), mas também as Mesorregiões Centro Ocidental e Sudoeste Rio-Grandense, com 13\% e 11\% foram relevantes. Mesmo nas mesorregiões com menor participação percentual em relação ao total, como os casos de Centro Oriental (5,5\%), Nordeste (5,4\%) e Metropolitana (2,2\%), é possível verificar o crescimento de $M v_{t}$.

Segundo empresários do segmento, entrevistados na presente pesquisa, a comercialização de fertilizantes acontece de duas formas: 1) agenciamento, que resultam da intermediação de operações comerciais. Nesta modalidade de negócio, as margens médias de ganho das empresas variam de $1 \%$ a $2 \%$ sobre o montante comercializado, e; 2 ) revenda de fertilizantes que foram adquiridos pelas varejistas. Nesta modalidade, a margem de comercialização se situa ao redor dos $15 \%$ sobre o montante comercializado. 
Considerando a existência destas duas modalidades no comércio de fertilizantes, apurou-se, em entrevista com empresários do segmento, que a margem de comercialização média do varejo, englobando as negociações com fertilizantes, fica próxima de $4,5 \%$.

Este foi o parâmetro adotado para mensurar o volume apropriado, pelas empresas e cooperativas varejistas, nas operações que envolvem o comércio atacadista de fertilizantes $\left(M v_{\text {tfertilizantes }}\right)$. A Tabela 6 apresenta os resultados encontrados.

Tabela 6. Margem de Comercialização (4,5\%) no comércio de fertilizantes (em R\$ milhões de 2017): ano-safra 2000/2001 a 2017/2018

\begin{tabular}{|ccccccccc}
\hline Safra & $\begin{array}{c}\text { Noroes- } \\
\text { te }\end{array}$ & $\begin{array}{c}\text { Centro } \\
\text { Ocidental }\end{array}$ & $\begin{array}{c}\text { Sudo- } \\
\text { este }\end{array}$ & $\begin{array}{c}\text { Sude- } \\
\text { ste }\end{array}$ & $\begin{array}{c}\text { Centro } \\
\text { Oriental }\end{array}$ & $\begin{array}{c}\text { Nordes- } \\
\text { te }\end{array}$ & $\begin{array}{c}\text { Metro- } \\
\text { politana }\end{array}$ & Total \\
\hline $2000 / 2001$ & 35,91 & 3,32 & 2,09 & 0,51 & 0,94 & 1,38 & 0,03 & 44,18 \\
\hline $2001 / 2002$ & 26,62 & 2,85 & 1,72 & 0,41 & 0,81 & 1,01 & 0,06 & 33,48 \\
\hline $2002 / 2003$ & 27,52 & 3,27 & 1,96 & 0,55 & 0,91 & 1,29 & 0,08 & 35,59 \\
\hline $2003 / 2004$ & 37,51 & 5,38 & 3,53 & 0,88 & 1,52 & 1,92 & 0,14 & 50,88 \\
\hline $2004 / 2005$ & 41,38 & 6,79 & 5,17 & 1,22 & 1,92 & 2,43 & 0,31 & 59,22 \\
\hline $2005 / 2006$ & 31,80 & 5,73 & 4,23 & 1,22 & 1,53 & 2,06 & 0,28 & 46,85 \\
\hline $2006 / 2007$ & 27,14 & 5,08 & 3,05 & 0,80 & 1,33 & 1,86 & 0,22 & 39,48 \\
\hline $2007 / 2008$ & 29,17 & 5,28 & 3,19 & 0,91 & 1,39 & 1,97 & 0,22 & 42,13 \\
\hline $2008 / 2009$ & 70,75 & 13,46 & 7,44 & 2,17 & 3,51 & 4,83 & 0,49 & 102,65 \\
\hline $2009 / 2010$ & 53,63 & 10,13 & 4,97 & 1,84 & 2,77 & 3,95 & 0,38 & 77,67 \\
\hline $2010 / 2011$ & 37,27 & 6,94 & 3,80 & 1,52 & 1,89 & 2,88 & 0,25 & 54,55 \\
\hline $2011 / 2012$ & 32,46 & 6,23 & 3,12 & 1,45 & 1,73 & 2,48 & 0,25 & 47,71 \\
\hline $2012 / 2013$ & 39,91 & 8,19 & 5,15 & 2,11 & 2,85 & 3,18 & 0,62 & 62,01 \\
\hline $2013 / 2014$ & 101,42 & 22,38 & 16,55 & 8,58 & 9,07 & 8,57 & 2,34 & 168,91 \\
\hline $2014 / 2015$ & 62,33 & 14,34 & 10,68 & 6,79 & 5,96 & 5,63 & 1,81 & 107,53 \\
\hline $2015 / 2016$ & 72,58 & 17,07 & 14,30 & 8,66 & 7,02 & 6,81 & 2,25 & 128,69 \\
\hline $2016 / 2017$ & 68,67 & 16,12 & 13,40 & 8,91 & 6,71 & 6,56 & 2,41 & 122,79 \\
\hline $2017 / 2018$ & 63,39 & 14,86 & 12,26 & 8,94 & 6,26 & 6,16 & 2,51 & 114,37 \\
\hline Média & 47,75 & 9,30 & 6,48 & 3,19 & 3,23 & 3,61 & 0,81 & 74,37 \\
\hline Mediana & 38,71 & 6,87 & 4,60 & 1,48 & 1,90 & 2,68 & 0,29 & 56,88 \\
\hline Desv. Pad. & 20,45 & 5,53 & 4,63 & 3,28 & 2,50 & 2,20 & 0,92 & 38,64 \\
\hline Máximo & 101,42 & 22,38 & 16,55 & 8,94 & 9,07 & 8,57 & 2,51 & 168,91 \\
\hline Mínimo & 26,62 & 2,85 & 1,72 & 0,41 & 0,81 & 1,01 & 0,03 & 33,48 \\
\hline
\end{tabular}

Fonte: Elaboração própria com base em Brasil (2018c) e Brasil (2018d).

A margem de comercialização do varejo, no segmento de fertilizantes é a menor entre os três insumos analisados. Por outro lado, o volume de negócios é maior quando comparado aos demais.

Em geral, observou-se que a apropriação, pelo varejo, resultante da comercialização de fertilizantes, cresceu cerca de $\mathrm{R} \$$ 44,18 mi para $\mathrm{R} \$$ 114,47 mi no período analisado. Estes resultados, somados aos demais, permitem mensurar a importância econômica do segmento de fornecimento de insumos para as lavouras de soja nos municípios produtores do Rio Grande do Sul. 
Neste aspecto, o segmento de comercialização de defensivos agrícolas é o principal destaque entre os analisados, pois permite ao varejo operar com margens médias próximas de $20 \%$.

$\mathrm{Na}$ Tabela 7, apresentou-se a margem de varejo do segmento de defensivos $\left(M v_{\text {tdefensivos }}\right)$, que representa o valor efetivamente apropriado pelo varejo no segmento em questão para os anos-safras de 2000/2001 a 2017/2018.

Tabela 7. Margem de Comercialização (20\%) no comércio de defensivos (em R\$ milhões de 2017): ano-safra 2000/2001 a 2017/2018

\begin{tabular}{|c|c|c|c|c|c|c|c|c|}
\hline Safra & $\begin{array}{c}\text { Noroes- } \\
\text { te }\end{array}$ & $\begin{array}{c}\text { Centro } \\
\text { Ocidental }\end{array}$ & $\begin{array}{l}\text { Sudo- } \\
\text { este }\end{array}$ & $\begin{array}{l}\text { Sude- } \\
\text { ste }\end{array}$ & $\begin{array}{l}\text { Centro } \\
\text { Oriental }\end{array}$ & $\begin{array}{c}\text { Nordes- } \\
\text { te }\end{array}$ & $\begin{array}{l}\text { Metro- } \\
\text { politana }\end{array}$ & Total \\
\hline $2000 / 2001$ & 151,42 & 13,99 & 8,80 & 2,15 & 3,98 & 5,82 & 0,15 & 186,31 \\
\hline $2001 / 2002$ & 119,48 & 12,80 & 7,74 & 1,86 & 3,63 & 4,54 & 0,26 & 150,30 \\
\hline $2002 / 2003$ & 125,70 & 14,92 & 8,96 & 2,53 & 4,17 & 5,91 & 0,38 & 162,55 \\
\hline $2003 / 2004$ & 131,46 & 18,86 & 12,37 & 3,09 & 5,32 & 6,73 & 0,48 & 178,31 \\
\hline $2004 / 2005$ & 153,90 & 25,26 & 19,22 & 4,53 & 7,13 & 9,05 & 1,14 & 220,23 \\
\hline $2005 / 2006$ & 155,45 & 28,02 & 20,67 & 5,95 & 7,49 & 10,08 & 1,35 & 229,02 \\
\hline $2006 / 2007$ & 237,41 & 44,45 & 26,66 & 7,02 & 11,67 & 16,28 & 1,91 & 345,40 \\
\hline $2007 / 2008$ & 169,60 & 30,72 & 18,53 & 5,26 & 8,10 & 11,44 & 1,26 & 244,92 \\
\hline $2008 / 2009$ & 159,62 & 30,36 & 16,77 & 4,89 & 7,92 & 10,91 & 1,11 & 231,58 \\
\hline $2009 / 2010$ & 158,44 & 29,91 & 14,70 & 5,44 & 8,17 & 11,68 & 1,11 & 229,45 \\
\hline $2010 / 2011$ & 117,14 & 21,82 & 11,94 & 4,76 & 5,93 & 9,05 & 0,80 & 171,44 \\
\hline $2011 / 2012$ & 130,60 & 25,06 & 12,54 & 5,84 & 6,95 & 9,99 & 1,01 & 191,98 \\
\hline $2012 / 2013$ & 123,77 & 25,41 & 15,97 & 6,55 & 8,83 & 9,85 & 1,94 & 192,31 \\
\hline $2013 / 2014$ & 222,77 & 49,16 & 36,35 & 18,84 & 19,93 & 18,82 & 5,13 & 371,00 \\
\hline $2014 / 2015$ & 233,10 & 53,62 & 39,96 & 25,38 & 22,28 & 21,04 & 6,77 & 402,15 \\
\hline $2015 / 2016$ & 274,31 & 64,52 & 54,03 & 32,73 & 26,54 & 25,74 & 8,52 & 486,39 \\
\hline $2016 / 2017$ & 265,46 & 62,33 & 51,81 & 34,45 & 25,94 & 25,35 & 9,31 & 474,64 \\
\hline $2017 / 2018$ & 282,64 & 66,25 & 54,66 & 39,88 & 27,90 & 27,47 & 11,18 & 509,97 \\
\hline Média & 178,46 & 34,30 & 23,98 & 11,73 & 11,77 & 13,32 & 2,99 & 276,55 \\
\hline Mediana & 156,95 & 28,97 & 17,65 & 5,64 & 8,01 & 10,49 & 1,20 & 229,23 \\
\hline Desv. Pad. & 55,90 & 17,31 & 15,69 & 12,20 & 8,27 & 7,12 & 3,43 & 117,82 \\
\hline Máximo & 282,64 & 66,25 & 54,66 & 39,88 & 27,90 & 27,47 & 11,18 & 509,97 \\
\hline Mínimo & 117,14 & 12,80 & 7,74 & 1,86 & 3,63 & 4,54 & 0,15 & 150,30 \\
\hline
\end{tabular}

Fonte: Elaboração própria com base em Brasil (2018c) e Brasil (2018d).

As séries estatísticas estimadas permitem observar que a margem bruta de comercialização do varejo, derivadas das operações com defensivos, cresceu de $R \$$ 186,31 milhões para $\mathrm{R} \$ 509,97$ milhões no período analisado.

As mesorregiões Noroeste, Centro Ocidental e Sudoeste concentram 79\% do total apropriado pelo segmento e, mesmo na mesorregião Noroeste, onde a área plantada não oscilou significativamente, a margem cresceu de $R \$ 151$ mi para $R \$ 282$ mi.

Na Figura 3, apresentou-se a síntese dos resultados e permite comparar o total das margens brutas por insumo analisado. 
Figura 3. Margem de Comercialização das Empresas de Insumos Agrícolas ( $\mathrm{R} \$$ milhões de 2017) em sementes, fertilizantes e defensivos na produção de soja do

Rio Grande do Sul: ano-safra 2000/2001 a 2017/2018

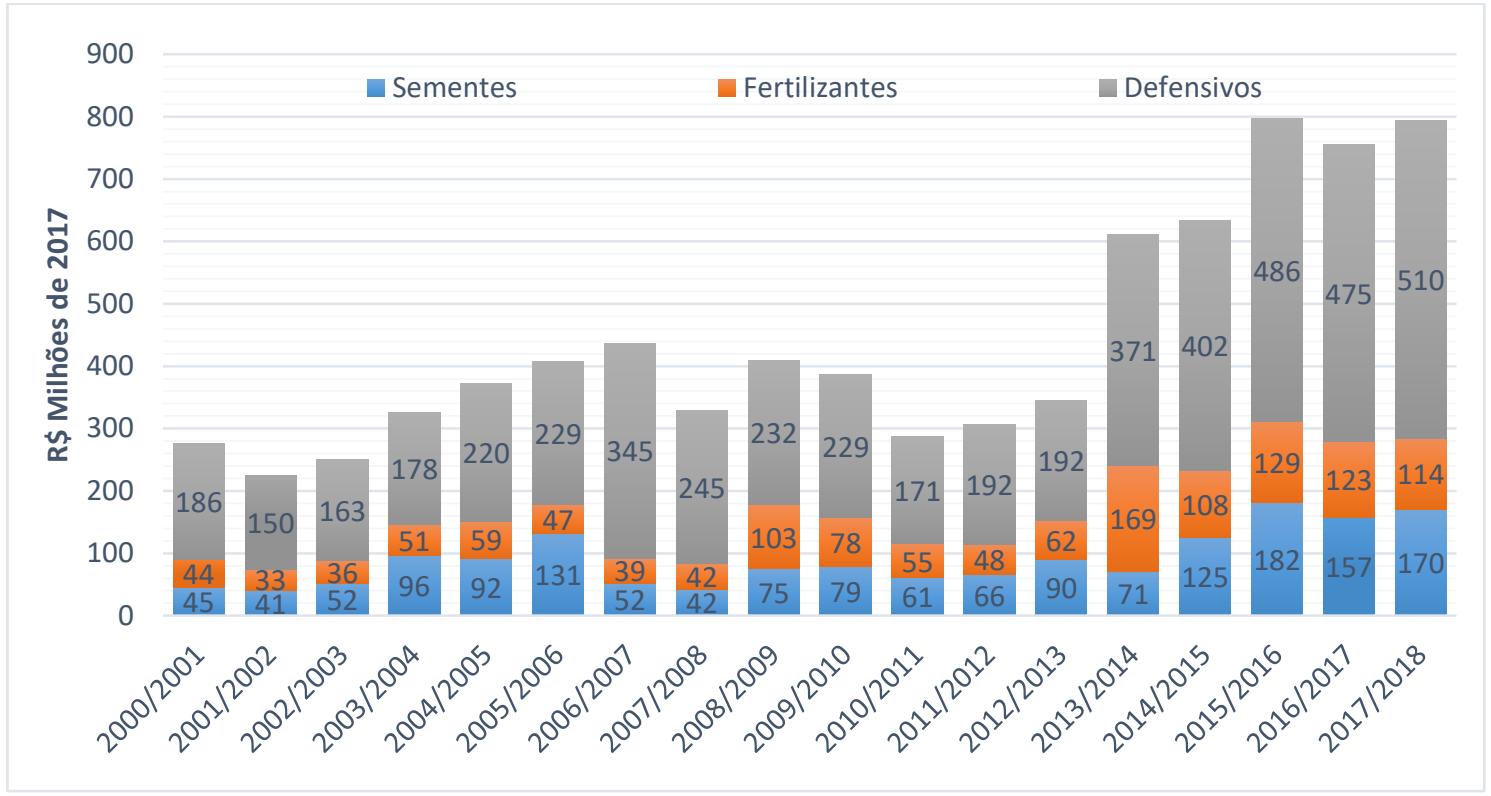

Fonte: Elaboração própria com base em Brasil (2018c) e Brasil (2018d).

É possível observar que os defensivos se caracterizam, entre os produtos analisados, como a principal fonte de receita das empresas e cooperativas.

A importância deste mercado se revela na perspectiva comparativa, onde é possível observar que, ao longo do período analisado, em nenhum dos anos a margem bruta de comercialização do varejo, derivada das vendas de defensivos, foi inferior a 55\% do total (quando comparados os valores agregados dos ganhos com sementes, fertilizantes e defensivos). Também, ajudam a mensurar a importância econômica destas atividades.

Por outro lado, apesar da importância econômica revelada pelas amplas cifras envolvidas nos negócios de insumos e exportações, a presente pesquisa não avançou no sentido de identificar o grau de concentração nas atividades relacionadas aos encadeamentos retrospectivos e prospectivos gerados pela lavoura de soja, bem como o número de empregos que estes geram. Neste contexto, os estudos de Costa e Santana (2014) apontam para os elevados graus de concentração da atividade econômica ao longo da cadeia produtiva da soja e Rhoden et al. (2017) ajudam a entender os impactos desta cadeia produtiva no mercado formal de trabalho, elemento que mostra a importância da realização de novas pesquisas que abordem aspectos que não foram objeto de análise do presente estudo.

\section{Considerações Finais}

O agronegócio é um dos principais segmentos da economia brasileira e a sua importância é comprovada pela capacidade de agregar renda e elevar o saldo comercial até mesmo em momentos de crise econômica. 
Na economia do estado do Rio Grande do Sul, o agronegócio responde pela maior parte dos superávits comerciais e estimula o desenvolvimento de um significativo número de atividades econômicas nas diversas cadeias produtivas que têm por escopo a produção de alimentos, fibras e bioenergia.

A cadeia produtiva da soja, principal do agronegócio brasileiro e proeminente do agronegócio gaúcho, além de gerar renda e saldo comercial no Brasil e no Rio Grande do Sul, agrega um conjunto de atividades com potencial para estimular as relações econômicas em nível local.

Nesta perspectiva, as respostas para o problema do presente estudo, que foi norteado pela questão "em que medida a lavoura de soja contribuiu para o estabelecimento de atividades retrospectivas e para o faturamento bruto das empresas e cooperativas que atuam no segmento de venda de sementes, fertilizantes e defensivos no estado do Rio Grande do Sul?", são as seguintes:

a. A lavoura de soja foi responsável por gerar um volume de negócios ao redor de $R \$ 1,42$ bilhão em sementes no ano-safra de 2017/2018. Deste montante, cerca de $\mathrm{R} \$ 170,3$ milhões foram apropriados pelo comércio atacadista e parte deste recurso foi destinado para o pagamento de funcionários, impostos e outros elementos de custos das empresas;

b. Somente em fertilizantes utilizados na lavoura de soja, foram destinados cerca de $\mathrm{R} \$ 2,54$ bilhões no ano-safra de 2017/2018. Deste montante, a estimativa é de que o mercado varejista apropriou 114,37 milhões, valor este que, se pressupõe, ficou na economia dos municípios, pois as empresas em questão são majoritariamente de abrangência municipal/regional;

c. O segmento de defensivos para a lavoura de soja alcançou um faturamento bruto de $\mathrm{R} \$ 2,55$ bilhões, dos quais, $\mathrm{R} \$ 509,97$ milhões foram apropriados pelo comércio varejista.

Portanto, além de dar origem à principal cadeia produtiva do agronegócio brasileiro e gaúcho, a lavoura de soja se constitui em uma grande catalisadora de negócios e possui capacidade de estimular as atividades retrospectivas, notadamente que produzem insumos para as lavouras.

Estes resultados, associados às dificuldades logísticas enfrentadas pelo segmento nos últimos anos, corroboram a necessidade de investimento em infraestrutura, pois uma vez afetada em sua competitividade, muitos setores e economias enfrentarão dificuldades.

Pode-se destacar como limitações do presente trabalho, o fato de não incorporar nas análises os impactos econômicos causados pelas barreiras que os principais importadores impõem. Neste sentido, faz-se pertinente novos estudos visando identificar as principais barreiras econômicas e o custo causado pelas mesmas, o que pode ser mensurado com Modelos de Equilíbrio Geral Computável (MEGC).

\section{REFERÊNCIAS}

BERALDO, J. B. L.; FIGUEIREDO, M. G. de. Formação do preço de fertilizantes em Mato Grosso. Revista de Política Agrícola, v. 25, n. 3, p. 16-20, 2016. 
BRASIL. Ministério da Agricultura Pecuária e Abastecimento. Secretaria de Relações Internacionais do Agronegócio. Balança Comercial e Balança Comercial do Agronegócio. Brasília. 2018a. Disponível em: < http://www.agricultura.gov.br/assuntos/relacoes-internacionais/estatisticas-decomercio-exterior>. Acesso em: 31 mar 2017.

BRASIL. Ministério da Agricultura Pecuária e Abastecimento. AGROSTAT Estatísticas de Comércio Exterior do Agronegócio Brasileiro. Brasília. 2018b. Disponível em: < http://sistemasweb.agricultura.gov.br/pages/AGROSTAT.html>. Acesso em: 31 mar 2017.

BRASIL, Companhia Nacional de Abastecimento (CONAB). Levantamento dos Custos de Produção de soja, milho e trigo. Companhia Nacional de Abastecimento. Brasília: Conab, 2018c. Disponível em: <http://www.conab.gov.br/conteudos.php?a=1554\&t=2>. Acesso em 11/08/2018.

BRASIL. Instituto Brasileiro de Geografia e Estatística. SIDRA - Produção Agrícola Municipal. Brasília. 2018d. Disponível em: <https://sidra.ibge.gov.br/home/ipca15/brasil>. Acesso em 15 jul. 2016.

BRASIL, Companhia Nacional de Abastecimento (CONAB). Série Histórica de Produtividade por Unidades da Federação. Companhia Nacional de Abastecimento. Brasília: Conab, 2017. Disponível em: <http://www.conab.gov.br/>. Acesso em 26/11/2016.

BRASIL. IBGE, Diretoria de Geociências, Coordenação de Geografia. 2. Divisão do Brasil em mesorregiões e microrregiões geográficas. Rio de Janeiro. 1990. Disponível em: Disponível em < https://www.ibge.gov.br/geociencias/organizacaodo-territorio/divisao-regional/>. Acesso em 02 fev. 2017.

BRUM, A. L. O Brasil na história da economia mundial da soja. Departamento de Economia e Contabilidade, Universidade de ljuí. Textos para discussão n² 2. ljuí, Unijuí, 1992. 200 p.

CEPEA, Centro de Estudos Avançados em Economia Aplicada (ESALQ/USP). PIB do Agronegócio Brasileiro. Piracicaba/SP. 2017.

Disponível em <http://www.cepea.esalq.usp.br/br/pib-do-agronegociobrasileiro.aspx>. Acesso em 31 mar 2017.

COSTA, N. L.; SANTANA, A. C. de. Estudo da concentração de mercado ao longo da cadeia produtiva da soja no Brasil. Revista de Estudos Sociais, v. 16, n. 32, p. 111-135, 2014. Disponível em: <http://dx.doi.org/10.19093/res.v16i32.1853>. Acesso em $14 / 05 / 2018$.

COSTA, N. L.; SANTANA, AC de. Poder de mercado e desenvolvimento de novas cultivares de soja transgênicas e convencionais: análise da experiência brasileira. Revista de Ciências Agrárias/Amazonian Journal of Agricultural and 
Environmental Sciences, v. 56, n. 1, p. 61-68, 2013. Disponível em: <http://dx.doi.org/10.4322/rca.2013.003>. Acesso em 05/05/2014

DAVIS, J. H. From Agriculture to Agribusiness. Harvard Business Review, v. 34, p. 107-115, 1956.

DAVIS, J. H.; GOLDBERG, R. A. A concept of agribusiness. Boston: Division of Research, Graduate School of Business Administration, Harvard University, 1957.

GASQUES, J. G., REZENDE, G. C. D., VILLA VERDE, C. M., SALERNO, M. S., da CONCEIÇÃO, J. C. P., \& CARVALHO, J. C. D. S. Desempenho e crescimento do agronegócio no Brasil. Ipea. 2004.

GREENE, W. H. Econometrics Analysis. 6.ed. New Jersey: Pearson Education, 2008.

GOMES, S. C.; SANTANA, A. C.; MOREIRA, M. G. P.; ZURUTUZA, J. D. C.; COSTA, E. J. $M$. Efeitos de encadeamentos e os multiplicadores da economia paraense:

evidências do setor agropecuário. Boletim Estatísticas Públicas, v.1, p.7 -18, 2016.

HIRSCHMAN, A. O. The strategy of economic development. Boulder, CO: Westview Press, 1988.

JANK, M. S.; NASSAR, A. M.; TACHINARDI, M. H. Agronegócio e comércio exterior brasileiro. Revista USP, n. 64, p. 14-27, 2005.

MENDES, J. T. G.; JÚNIOR, J. B. P. Agronegócio: uma abordagem econômica.

Pearson Prentice Hall, 2007.

RHODEN, A. C.; COSTA, N. L.; SANTANA, A. C.; GABBI, M. T. T.; JANEQUE, R. A. Analysis of the generation of formal employment by the soybeans production chain in the Rio Grande do Sul State/Brazil: 2002-2015. International Journal of Development Research, v. 7, p. 18062-18070, 2017.

RHODEN, A. C.; COSTA, N. L.; SANTANA, A. C.; OlIVEIRA, G. N. O.; GABBI, M. T. T. Análise das tendências de oferta e demanda para o grão, farelo e óleo de soja no Brasil e nos principais mercados globais. Desenvolvimento em Questão, v.16, p.93 112, 2020.

SANTANA, A. C. de. Métodos quantitativos em economia: elementos e aplicações. Belém: Ufra, p. 485, 2003.

SANTANA, A. C.; CAMPOS, A. C. Análise intersetorial da economia brasileira: uma aplicação da matriz de contabilidade social. Revista de Economia e Sociologia Rural, v.32, p.7 - 22, 1994.

SEVERINO, A. J. Metodologia do trabalho científico. Editora Cortez, 2002. 
UNITED STATES DEPARTMENT OF LABOR. Bureau of Labor Statistcs. Washington, DC. 2018. Disponível em <https://www.bls.gov/bls/contact.htm>. Acesso em 30 mar 2018.

THEISEN, G.; VERNETTI JUNIOR, F. J.; SILVA, J. J. C. Soja na Metade Sul do Rio Grande do Sul: cuidados em tempos de El-niño. Revista Plantio Direto, p. 14 - 15, 01 nov. 2009.

THUSWOHL, M. Grupo de Seis Empresas Controla Mercado Global de Transgênicos. Repórter Brasil, São Paulo, 2013.

VERGARA, S. Projetos e relatórios de pesquisa em administração. São Paulo: Atlas, 2014.

Nilson Luiz Costa. Economista, Doutor em Ciências Agrárias. É docente da Universidade Federal de Santa Maria, onde coordena o Núcleo de Pesquisas em Economia do Agronegócio (NPEA), está vinculado ao Programa de PósGraduação em Agronegócios - Mestrado Acadêmico e ao Curso de Graduação em Ciências Econômicas. Av. Independência, $\mathrm{n}^{\circ}$ 3751. Bairro Vista Alegre. Palmeira das Missões/RS. CEP: 98300-000. E-mail nilson.costa@ufsm.br

Antônio Cordeiro de Santana. Engenheiro Agrônomo, Doutor em Economia Aplicada. É docente da Universidade Federal Rural da Amazônia, onde coordena o Grupo de Pesquisas em Cadeias Produtivas, Mercado e Desenvolvimento Sustentável e atua nos Cursos de Graduação em Agronomia, Medicina Veterinária e Zootecnia. Também é docente do Programa de Pós-Graduação em Desenvolvimento Sustentável do Trópico Úmido da Universidade Federal do Pará. E-mail acsufra@gmail.com

Daniel Arruda Coronel. Economista, Doutor em Economia Aplicada. É docente da Universidade Federal de Santa Maria, onde coordena a Editora UFSM, está vinculado ao Programa de Pós-Graduação em Agronegócios - Mestrado Acadêmico e aos Cursos de Graduação em Ciências Econômicas e Relações Internacionais. Av. Roraima n 1000. E-mail daniel.coronel@uol.com.br

Argemiro Luís Brum. Administrador de Empresas, Doutor em Sócio Economia do Desenvolvimento. É docente da Universidade Regional do Noroeste do Estado do Rio Grande do Sul (UNIJUÍ), onde coordena a Central Internacional de Análises Econômicas e de Estudos de Mercado Agropecuário (CEEMA), está vinculado ao Programa de Pós-Graduação em Desenvolvimento Regional Mestrado e Doutorado e ao Curso de Graduação em Administração. E-mail argelbrum@unijui.edu.br

Carlos André Corrêa de Mattos. Administrador de Empresas, Doutor em Ciências Agrárias. É docente da Universidade Federal do Pará (UFPA), onde é docente do Programa de Pós-Graduação em Administração - Mestrado o do curso de Graduação em Administração. E-mail cacmattos@gmail.com 
Submetido em:20/12/2018

Aprovado em: 04/06/2020

Como citar: COSTA, Nilson Luiz et al. Aspectos da importância do complexo soja no Brasil e no Rio Grande do Sul: 1997 - 2017. Redes (St. Cruz Sul, Online), Santa Cruz do Sul, v. 25, p. 1840-1863, nov. 2020. ISSN 1982-6745. doi:https://doi.org/10.17058/redes.v25i4.12735.

\section{CONTRIBUIÇÃO DE CADA AUTOR}

a. Fundamentação teórico-conceitual e problematização: Todos os autores

b. Pesquisa de dados e análise estatística: Nilson Luiz Costa

c. Elaboração de figuras e tabelas: Nilson Luiz Costa

d. Fotos: Não se aplica ao artigo

e. Elaboração e redação do texto: Todos os autores

f. Seleção das referências bibliográficas: Todos os autores

Fontes de financiamento: Não se aplica ao artigo 